\title{
COVID-19 epidemiology in a Mexican tertiary care hospital
}

César A. Arce-Salinas, ${ }^{1}$ Daniel López-Herrera, ${ }^{2}$ Adriana Hernández-Alarcón, ${ }^{3}$ Eva M. Luna-Rivera, ${ }^{4}$ Arely A. Bejarano-Juvera, ${ }^{5}$ Aditi K. Bustamante-Flores, ${ }^{5}$ Naomi Aguilar-Martínez, ${ }^{5}$ Jessica G. Azcorra-López, Berenice Cabañas-Espinosa, ${ }^{5}$ Yamile N. Esquivel-Torruco ${ }^{5}$ and Jesús Reyna-Figueroa ${ }^{5 *}$ ${ }^{1}$ Director's Office; ${ }^{2}$ Occupational Medicine Department; ${ }^{3}$ Outpatient Department; ${ }^{4}$ Teaching and Research Department; ${ }^{5}$ Department of Pediatrics. Petróleos Mexicanos, Hospital Central Sur de Alta Especialidad, Mexico City, Mexico

\begin{abstract}
Introduction: As a result of COVID-19, many hospitals underwent a conversion for the care for this disease. Objective: To analyze COVID-19 hospital epidemiological behavior from March to August 2020. Methods: Through a series of cases, COVID-19 epidemiological behavior at the hospital was analyzed, for which simple case rates, percentages and incidence of COVID-19 per 100 hospital discharges were estimated. Results: Out of 491 subjects who tested positive for SARS-CoV-2, 156 (31.7 \%) were hospitalized for clinical data of moderate to severe disease. Average age was 59.1 years; 121 cases (75\%) were discharged due to improvement, and 32 (20.5\%), due to death. Average age of those who died was 69.7 years, and the most affected age group was 60 to 80 years (45.4\%). Calculated lethality was 20.5 per 100 hospital discharges, while that calculated taking into account positive patients (outpatients and hospitalized patients) was 6.5. Conclusions: COVID-19 epidemiological behavior was similar to that described in other studies; however, lethality and mortality are above national average. The analysis of this and of the factors that favored it in our population is pending.
\end{abstract}

KEY WORDS: COVID-19. Mortality. Lethality. Mexico. Hospitalization.

\section{Epidemiología de COVID-19 en un hospital de tercer nivel mexicano}

\section{Resumen}

Introducción: A consecuencia de COVID-19, numerosos hospitales sufrieron una reconversión para la atención de esta enfermedad. Objetivo: Analizar el comportamiento epidemiológico hospitalario de COVID-19 entre marzo y agosto de 2020. Métodos: En una serie de casos se analizó el comportamiento epidemiológico de COVID-19 en un hospital de tercer nivel, para lo cual se estimaron frecuencias simples de casos, porcentajes e incidencia por cada 100 egresos hospitalarios. Resultados: De 491 sujetos con prueba positiva para SARS-CoV-2, 156 (31.7 \%) fueron hospitalizados por datos clínicos de enfermedad moderada a grave. La edad promedio fue de 59.1 años; 121 casos (75 \%) egresaron por mejoría y 32 (20.5\%), por defunción. El promedio de edad de quienes fallecieron fue de 69.7 años y el grupo etario más afectado fue el de 60 a 80 años (45.4\%). La letalidad calculada fue de 20.5 por 100 egresos hospitalarios, mientras que la calculada tomando en cuenta los pacientes positivos (ambulatorios y hospitalizados) fue de 6.5. Conclusiones: El comportamiento epidemiológico de COVID-19 fue similar al descrito en otros estudios; sin embargo, la letalidad y la mortalidad están por encima de la media nacional. Está pendiente el análisis de estas y de los factores que las favorecieron en nuestra población.

PALABRAS CLAVE: COVID-19. Mortalidad. Letalidad. México. Hospitalización. license (http://creativecommons.org/licenses/by-nc-nd/4.0/).
} 


\section{Introduction}

In December 2019, an outbreak of pneumonia of unknown etiology emerged in the city of Wuhan, Hubei province in China, which ultimately was called COVID-19, when the new coronavirus SARS-CoV-2 was identified in January 2020 as its causal agent. ${ }^{1}$ By March 2020, COVID-19 was declared a pandemic by the World Health Organization, which marked the initiation of a series of strategies for containment and mitigation, including social distancing and confinement in more than 170 countries. ${ }^{2,3}$ At the hospital level, a significant number of institutions of all countries underwent a reconversion in order to prioritize the care of SARS-COV-2-infected patients: they increased the number of available beds, increased the capacity of their intensive therapy facilities and acquired ventilators, hoping to have the capacity to respond without their functionality being exceeded; ${ }^{4}$ in addition, they strengthened their surveillance systems and adopted different containment strategies. ${ }^{5}$

In Mexico, COVID-19 epidemiological surveillance has been carried out through the organized and diligent work of health services of all states, with professionals dedicated to obtain thorough patient information based on an epidemiological evaluation of cases suspected of viral respiratory disease, which applies to any person who meets current operational definition, with subsequent notification to the electronic platform of the National Epidemiological Surveillance System, managed by the General Directorate of Epidemiology of the Ministry of Health and that is sustained by Articles 3, 137, 138 and 142 of the General Statute of Health $^{6}$ and sections $6.5,6.5 .1$ and 6.5.2 of Official Mexican Standard NOM-017-SSA-2-2012 for epidemiological surveillance. ${ }^{7}$ This system has the capacity to analyze the data and provide a solid vision that allows initiating, deepening or rectifying prevention and control actions; in addition, it establishes which diseases are subject to mandatory notification and investigation, including diseases caused by the influenza virus.

While COVID-19 operational definition has evolved according to epidemiological behavior and scientific findings regarding its transmission, geolocation, and clinical features, confirmed cases establish the positivity of a molecular biology test.

In-hospital epidemiological surveillance and reporting to information systems is the responsibility of a center, which should have infectology and epidemiology experts available, as well as medical-administrative personnel; in addition, it must cover several objectives, including keeping the information updated and making the necessary changes. ${ }^{8}$ The number of publications that address some specific topic about the COVID-19 pandemic has exponentially increased in recent months. Even so, case series of sequentially hospitalized patients for confirmed COVID-19 are scarce $^{9}$, and in Mexico they are practically inexistent. Therefore, the purpose of the study was to analyze COVID-19 epidemiological behavior in the population cared for by Petróleos Mexicanos Central South High Specialty Hospital, between March and August 2020.

\section{Methods}

To make a comparison of COVID-19 epidemiological behavior at Petróleos Mexicanos Central South Hospital with data reported at the national level and by Petróleos Mexicanos health services, the following sources were reviewed:

- COVID-19 cases weekly reports, published in the General Directorate of Epidemiology of the Ministry of Health Epidemiological Bulletin.

- Daily epidemiological reports from Petróleos Mexicanos health services.

- Petróleos Mexicanos Central South High Specialty Hospital database.

COVID-19 suspicion was considered according to the Federal Ministry of Health initial operational definition, which considered a suspicious case as a person of any age with mild or severe acute respiratory disease and who had experienced any of the following events or situations up to 14 days before the onset of symptoms:

- Having been in contact with a case of COVID-19, either confirmed or under investigation.

- Having traveled or stayed in countries with local community-based COVID-19 transmission (China, Hong Kong, South Korea, Japan, Italy, Iran and Singapore).

And, subsequently, the following criterion was added:

- Presence of at least two of the following signs and symptoms within the last seven days: cough, fever or headache (severe and persistent headache), accompanied by at least one of the following signs or symptoms: shortness of breath, appetite loss, joint or muscle pain, conjunctivitis, sore throat, and nasal congestion. 
A confirmed case was defined as a patient with a polymerase chain reaction positive result, with the test being performed in the institutional laboratory, endorsed by "Dr. Manuel Martínez Báez" Institute of Epidemiological Diagnosis and Reference.

For the analysis, case simple frequencies, COVID-19 percentages and incidence were estimated per 100 monthly hospital discharges. To estimate the incidence trend, a correlation coefficient (non-parametric) was used between the number of weeks and monthly incidence. Monthly change was estimated by simple linear regression. Hospital incidence rates were compared with institutional and national incidence rates with $95 \%$ confidence intervals. For crude death rate calculation, the ratio of COVID-19 deaths among the Central South Hospital beneficiary population was obtained, which was multiplied by 1000 . The case fatality rate was calculated with the proportion of deaths among SARS-COV-2-positive cases per 100.

\section{Results}

Out of 491 subjects with a SARS-CoV-2-positive test, $156(31.7 \%)$ were hospitalized for clinical data consistent with moderate to severe COVID-19; $103(66 \%)$ were males and $53(34 \%)$ were females. Patient mean age was $59.1 \pm 15.4$ years. The highest number of cases was reported in the 41-60 years age group, with $41 \%$, followed by the groups of 61 to 80 years, with $39.1 \% ; 21$ to 40 years, with $9.6 \% ; 81$ or more years, with $8.9 \%$; and 0 to 20 years, with $1.2 \%$ (one case of seven years and another of 14 ).

One hundred and twenty-one cases $(75 \%)$ were discharged due to improvement of the condition, $32(20.5 \%)$ due to death, two patients were transferred to another institution and one was voluntarily discharged. Mean hospitalization time was $12 \pm$ 10.2 days.

Average age of those who died was $69.7 \pm$ 12.9 years; the most affected age group was that of 60 to 80 years, with $45.4 \%$ of cases, followed by the groups of 40 to 60 years and 80 years or more, each one with $27.2 \%$.

According to the place of detection and initial care, 147 of the cases $(97 \%)$ were identified at the Respiratory Diseases Care Clinic; the remaining nine were identified at the Intensive Care Unit $(n=2)$, and in the departments of Internal Medicine $(n=3)$, General Surgery $(n=1)$, Emergency $(n=2)$ and Nephrology $(\mathrm{n}=1)$.

\section{Hospitalizations}

Average number of hospitalizations per month was 33.6 cases within the period from April to August 2020. The lowest frequency corresponded to the month of April, with seven cases (4.4\%), and the highest corresponded to May, with 52 cases (33.3\%). The figures reported from June to August corresponded to $57.7 \%$ of the cases, which was equivalent to an increase of $20.6 \%$ with regard to previous quarter $(p=0.05)$, as shown in figure 1 , where the increasing trend in the number of patients hospitalized for COVID-19 can also be observed: 50 \% from April to August (Spearman's rho $=0.77, p=0.001$ ).

\section{Case fatality rate and mortality}

The case fatality rate calculated in patients treated at Central South High Specialty Hospital was 20.5 per 100 hospital discharges, while the case fatality rate calculated taking into account positive patients (outpatients and inpatients) was 6.5 per 100 patients. Mortality was reported at a rate of 1.1 per 1000 Petróleos Mexicanos health system users. Of the study months, August had the highest percentage of deaths, with $40 \%(n=15)$, followed by June, with $25.6 \%$, July with $23.1 \%$ and April with $14.3 \%$ (Fig. 2).

\section{Discussion}

Central South High Specialty Hospital is part of Petróleos Mexicanos health services; it is a tertiary care center with an estimated population of 27,000 beneficiaries. For the care of patients affected by the COVID-19 pandemic, it was reconverted in April 2020 in accordance with the Mexican health system national care agreement.

The data of highest interest found in our series are the case fatality and crude mortality rates reported at the hospital. Comparatively, the case fatality rate in hospitalized patients was $100 \%$ higher than that reported in the country and $20 \%$ higher than that recorded by Pemex health services. However, when analyzing the case fatality rate of patients with COVID-19, and taking into account both positive patients who were hospitalized and those treated as outpatients, the figures change dramatically: it was $61.9 \%$ lower with regard to the national rate and 39.6 $\%$ lower than those reported in the rest of Petróleos 


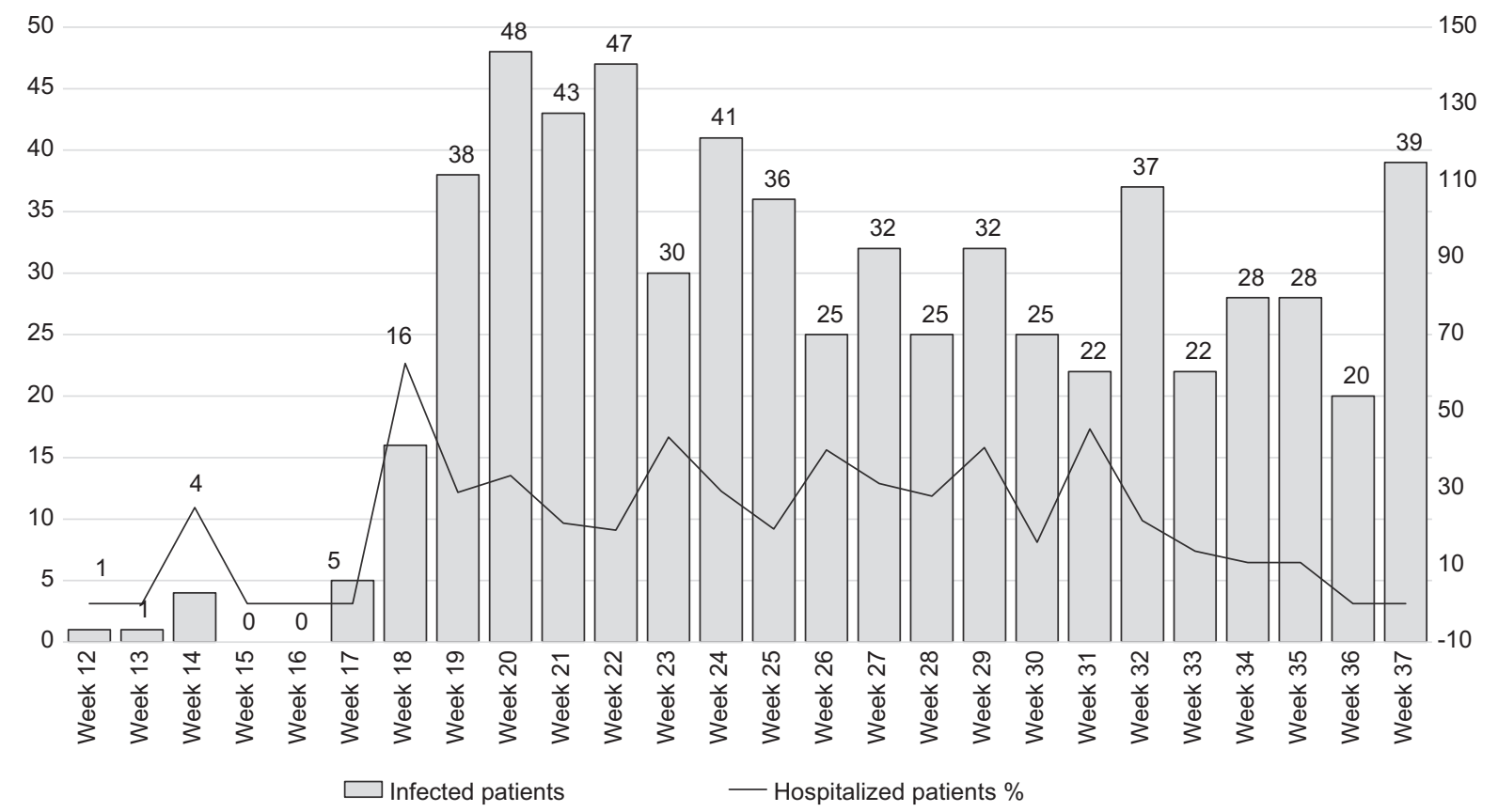

Figure 1. Percentage of patients hospitalized for COVID-19 in relation to patients with a positive test cared for at Central South High Specialty Hospital.

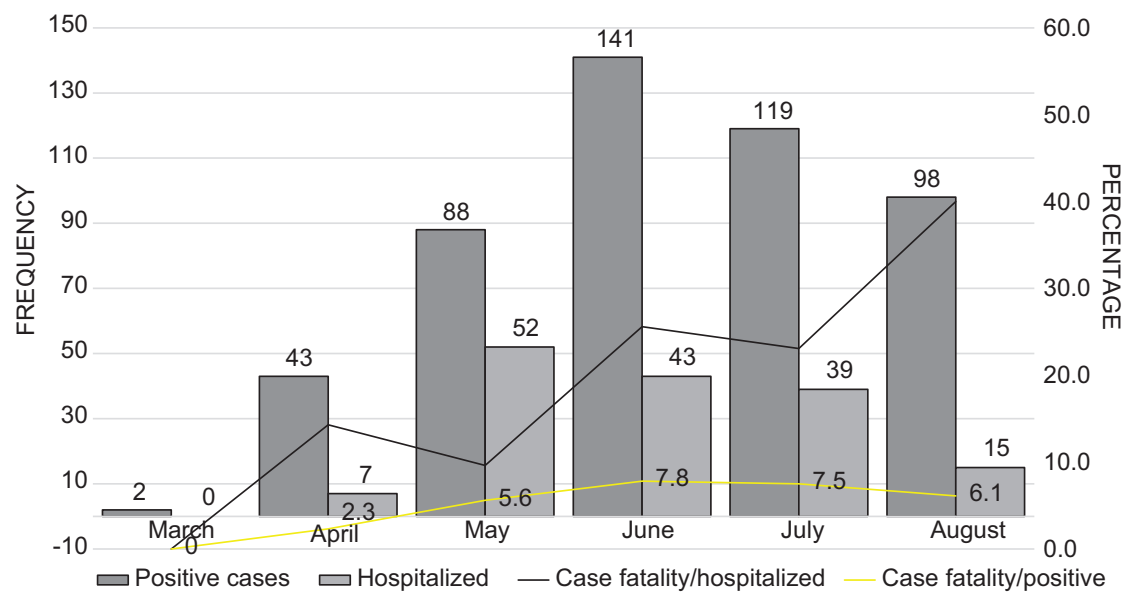

Figure 2. Case fatality rate per month at Central South High Specialty Hospital, according to deaths/positive cases (including outpatients) and deaths/hospitalizations.

Mexicanos health services. Mortality was higher than that reported in both cases, and the graphic comparison can be observed in figure 3 . Some explanations can be given considering the population and its characteristics. In this regard, some authors mention that COVID-19 case fatality rate depends on the severity of the case; particularly, Central South High Specialty Hospital admitted for hospitalization only patients with serious and very serious conditions, a strategy adopted to avoid hospital overcrowding (along with daily monitoring of home-confined positive patients in order to detect complications). Case fatality rate in our series was similar to that of hospitals that treat patients with serious associated diseases, such as cancer, in whom up to $28.6 \%$ has been described. ${ }^{10}$ However, the design of this series cannot address the complexity of this situation, and the results are not intended to make an analysis of the causes. 


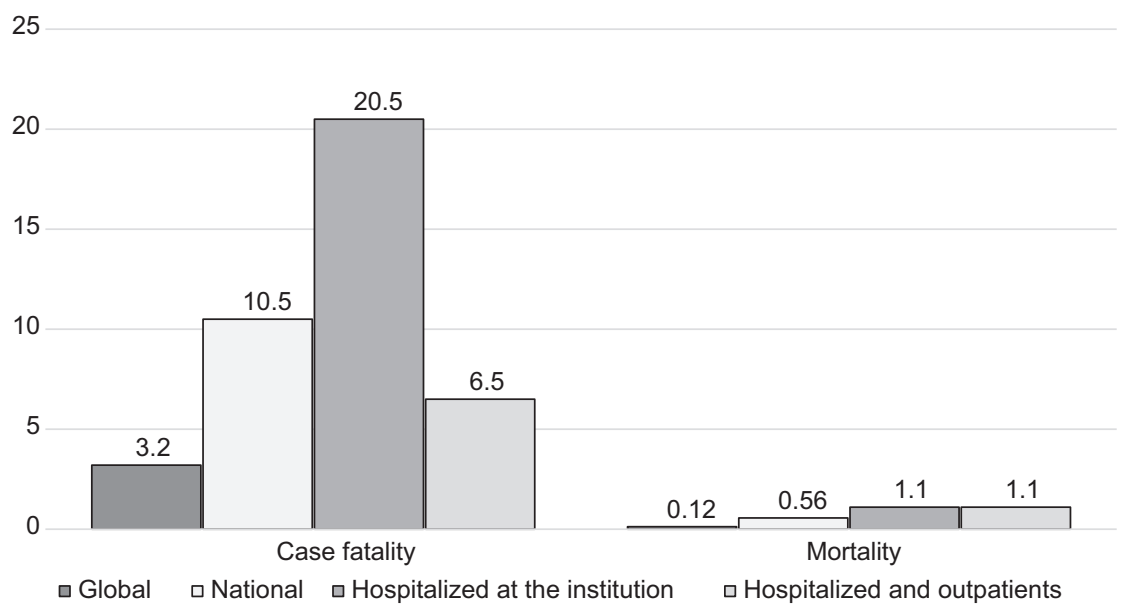

Figure 3. Comparison of Central South Hospital mortality and case fatality rates with those observed globally, nationally and at Petróleos Mexicanos health services.

60000

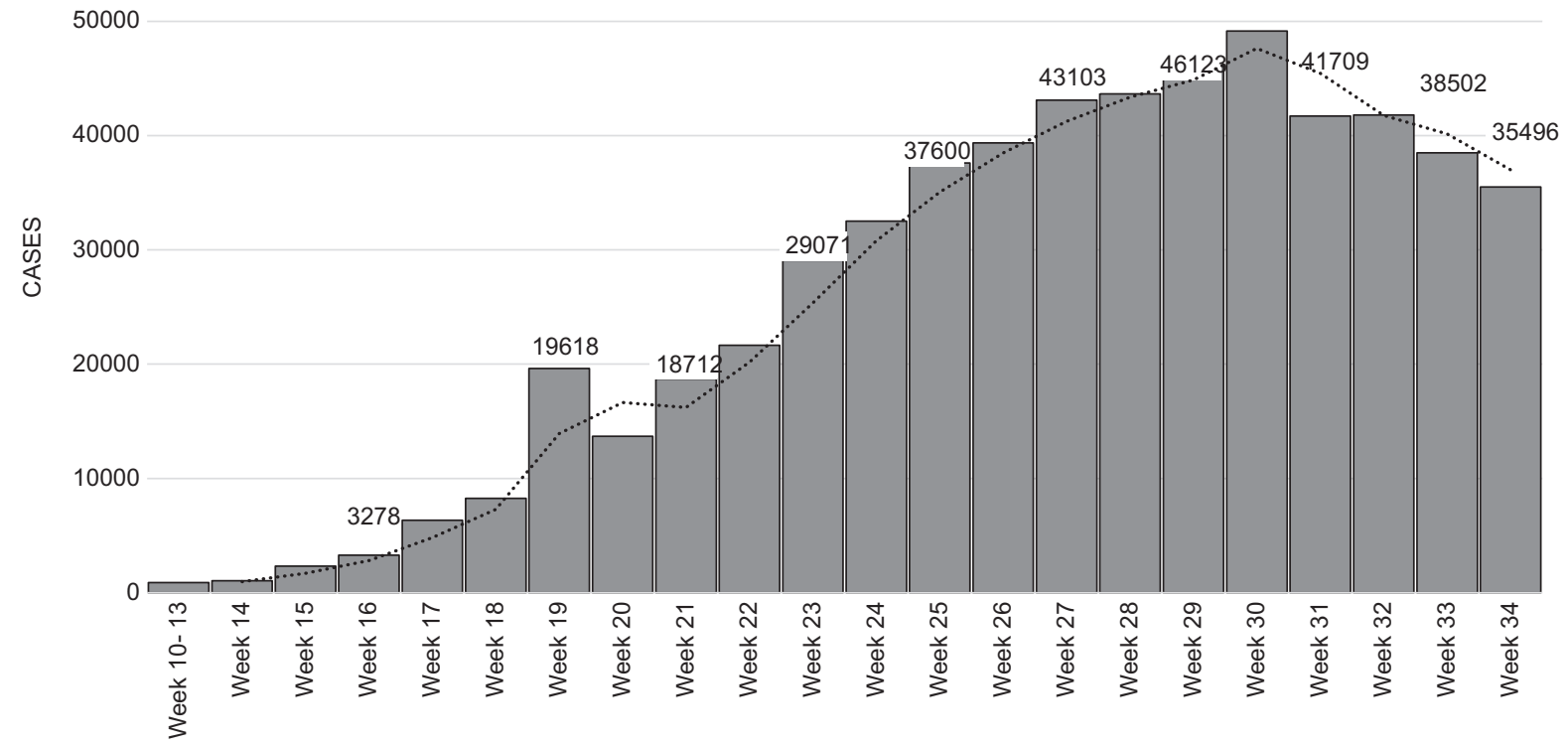

Figure 4. Number of cases in Mexico from epidemiological week 10 to 34 (March to August 2020). Source: Boletín Epidemiológico, Sistema Nacional de Vigilancia Epidemiológica, Sistema Único de Información, Dirección General de Epidemiología.

By September 2020, global epidemiological data indicated that COVID-19 had been responsible for nearly one million deaths $(3.2 \%)$ out of a total of 31 million cases. In Mexico, according to the analyzed notifications, by September 22, 684,113 cases and 72,179 deaths had been reported, with a case fatality rate of 10.5 per 100 cases,$^{11}$ and a crude death rate of 0.56 per 1000 population (a calculation in which a population of 127 million was considered for Mexico according to National Institute of Statistics and Geography latest report). By epidemiological week 35 of 2020 (corresponding to the last week of August), 573,885 confirmed cases had been reported; at week 29 , the highest number of cases occurred within the analyzed period (Fig. 4).

At Petróleos Mexicanos health services, according to official figures, by August 30, 2020, 7,661 cases of COVID-19 had been reported after the performance 
of 12,393 tests (61.8\% positivity), as well as 1,258 deaths (case fatality rate of 16.4 per 100 positive cases) and a crude death rate of 1.6 people per 1000 (a calculation that took 765,000 beneficiaries into account).

Mean age was similar to that of other series if the interquartile analysis is considered,,$^{9,12}$ while the percentage of hospitalizations was similar to that reported in other analyses. ${ }^{13}$

\section{Limitations}

This study has several limitations. First, the study population only included patients from the Central South High Specialty Hospital area of influence; second, data were collected from the electronic health records database, which hindered the level of detail that is possible with medical records manual review. Third, subgroup descriptive statistics were not adjusted for potential confounders, and describing the population or its demographic characteristics was neither intended.

\section{Conflict of interests}

The authors declare that they have no conflicts of interest.

\section{Funding}

This research did not receive any specific grants from agencies of public, commercial, or non-profit sectors.

\section{Ethical disclosures}

Protection of human and animal subjects. The authors declare that no experiments were performed on humans or animals for this research.

Confidentiality of data. The authors declare that no patient data appear in this article.

Right to privacy and informed consent. The authors declare that no patient data appear in this article.

\section{References}

1. Kannan S, Shaik Syed Ali P, Sheeza A, Hemalatha K. COVID-19 (novel coronavirus 2019) - recent trends. Eur Rev Med Pharmacol Sci. 2020;24:2006ロ2011.

2. Sohrabi C, Alsafi Z, O'Neill N, Khan M, Kerwan A, Al-Jabir A, et al. World Health Organization declares global emergency: A review of the 2019 novel coronavirus (COVID-19). Int J Surg. 2020;76:71076.

3. Cruz AT, Zeichner SL, COVID-19 in children: initial characterization of the pediatric disease. Pediatrics. 2020;145:e20200834.

4. Kashi AH. COVID-19, urologists and hospitals. Urol J. 2020;17:327.

5. Chang YT, Lin CY, Tsai MJ, Hung CT, Hsu CW, Lu PL, Hou MF. Infection control measures of a Taiwanese hospital to confront the COVID-19 pandemic. Kaohsiung J Med Sci. 2020;36:296-304.

6. Ley General de Salud. Mexico: Secretaría de Salud; 2020.

7. Norma Oficial Mexicana NOM-017-SSA2-2012, para la vigilancia epidemiológica. Mexico: Diario Oficial de la Federación; 2013 Feb 19.

8. Lineamientos de reconversión hospitalaria. Versión 5 de abril, 2020. Mexico: Secretaría de Salud; 2020.

9. Richardson S, Hirsch JS, Narasimhan M, Crawford JM, McGinn T, Davidson $\mathrm{KW}$, et al. Presenting characteristics, comorbidities, and outcomes among 5700 patients hospitalized with COVID-19 in the New York City Area. JAMA. 2020;323:2052-2059.

10. Zhang L, Zhu F, Xie L, Wang C, Wang J, Chen R, Jia P, et al. Clinical characteristics of COVID-19-infected cancer patients: a retrospective case study in three hospitals within Wuhan, China. Ann Oncol. 2020;31:894-901.

11. Coronavirus Resource Center, Johns Hopkins University [Internet]. Baltimore, USA. Critical trends: tracking critical data. [Updated 2020 Sep. 22]. Available at: https://coronavirus.jhu.edu/data

12. Superman G, Fidel RA, Mallete KM, Hammen C, Abdulá H, Ente A, et al. Clinical characteristics and morbidity associated with coronavirus disease 2019 in a series of patients in Metropolitan Detroit. JAMA Netw Open. 2020;3:e2012270.

13. Price-Haywood EG, Burton J, Fort D, Seoane L. Hospitalization and mortality among black patients and white patients with Covid-19. N Engl J Med. 2020;382:2534-2543 